\author{
JAN WOLEŃSKI \\ University of Information, Technology and Management \\ Rzeszów \\ jan.wolenski@uj.edu.pl
}

\title{
ABSOLUTENESS OF TRUTH AND THE LVOV-WARSAW SCHOOL (TWARDOWSKI, KOTARBIŃSKI, LEŚNIEWSKI, LUKASIEWICZ TARSKI, KOKOSZYŃSKA)
}

\begin{abstract}
According to Twardowski, truth is if it is independent of temporal coordinates. This understanding was one of the main arguments against truth-relativism. Kotarbiński rejected this view as far the issue concerns sentences about the future, but he did not elaborated this idea from a logical point of view. Leśniewski offered an argument that truth is eternal if and only if it is sempiternal; Twardowski shared this opinion. Lukasiewicz rejected sempiternality but retained eternality. His main novelty consisted in applying three-valued logic to explain how it is possible that truth is not sempiternal. Lukasiewicz also pointed out that bivalence together with the principle of causality implies radical determinism. Kotarbiński accepted Leśniewski's criticism and he defended Twardowski's view in Elementy. Tarski did not explicitly addressed to the problem of absoluteness or temporality of truth. On the other hand, Kokoszyńska proposed an interpretation of the semantic theory of truth as absolute. It is possible to justify absoluteness of truth in semantics cum the principle of bivalence and show that bivalence does not imply determinism.
\end{abstract}

Keywords. Truth, absoluteness, eternality, sempiternality, temporality, truth-bearers.

The concept of truth was one of the most important philosophical topics investigated in the Lvov-Warsaw School (LWS for brevity). Most philosophers belonging to this group defended the absoluteness of truth. ${ }^{1}$ I selected Kazimierz Twardowski, Tadeusz Kotarbiński, Stanisław Leśniewski, Jan Łukasiewicz, Alfred Tarski and Maria Kokoszyńska as the most significant authors offering interesting logical argument for alethic, that is, pertaining to truth, absolutism and against truth-theoretic relativism. ${ }^{2}$ In most cases, I will not review truth-

\footnotetext{
${ }^{1}$ But not all. Edward Poznański and Aleksander Wundheiler were the most notable exceptions. They proposed in 1934 a variant of the consensus theory of truth as more accurate for the philosophy of science.

${ }^{2}$ One should also menton Kazimierz Ajdukiewicz, Tadeusz Czeżowski and Zygmunt Zawirski who also belonged to the logical wing of LWS. However, they did not developed new separate argument for alethic absolutism. Władysław Tatarkiewicz or Izydora Dąmbska opted for the absoluteness of truth from the point of view of axiological or/and epistemological absolutism.
} 
definitions proposed by the mentioned philosophers (a comprehensive account of related definitions can be found in WOLEŃSKI, SIMONS [1989]. ${ }^{3}$ In general, Twardowski and his most students accepted the classical truthdefinition. Perhaps the following scheme captures the basic intuition:

(*) A truth-bearer (sentence, proposition, statement, judgment, etc.) is true if and only if $A$ says that it is so and so and it is so and so. ${ }^{4}$

The scheme (*) was in LWS concretized in various ways, for instance, by the formula "the sentence of the form ' $a$ is $b$ ' is true if and only if the object denoted by the term $a$ possesses a property expressed by the predicate $b$. Note that LWS generally avoided the label 'the correspondence theory of truth' as misleading.

Twardowski, influenced by Bolzano and Brentano, offered classical arguments against relativism (see TWARDOWSKI [1900]). He did not define the concept of truth (at least in TWARDOWSKI [1900]) and simply identified truth with true proposition. His main problem concerns the question whether truth is absolute or relative. According to Twardowski an utterance $A$ is absolutely true if and only if $A$ is true at all times, all places and all conditions, but $A$ is relatively true if and only if $A$ is true at some times, some place or certain conditions. Twardowski mentioned the following examples of relatively true utterances:

(1) It is raining in Lvov today;

(2) This flower has a pleasant smell;

(3) Cold baths are healthy;

(4) It is morally wrong to conceal truth.

According to standard arguments of alethic relativism, (1) can be false tomorrow, even if it is true today and, moreover, can be true in Lvov, but false in Cracow, (2) is (or can be) true for some persons and flowers, but false for other persons or flowers, the truth-value of (3) depends on who uses cold baths and, finally, (4) is a derivative of moral views. Consequently, sentences, according to relativists, can change logical values dependently on times, places or circumstances.

Twardowski did not agree with the above account. First of all, he distinguished propositions and sentences. The former, but not the latter are proper bearers of truth. On the other hand, sentences frequently have not fixed meaning, because indexicals, temporal and spatial coordinates, occur in them. An appeal to special

\footnotetext{
${ }^{3}$ I will also not compare views about the (alethtic) absolutism/relativism controversy advanced in LWS with ideas proposed in other philosophical circle.

${ }^{4}$ I what follows, I will use the unified terminology, in particular, the nouns "proposition" and "sentences" are employed, even if original terminology employed the verb "judgment" or "statement"; I sometimes use the nun "utterance" in order to be terminologically neutral.
} 
changing circumstances constitutes another reason for having inexact meaning by sentences. If we eliminate elements generating having inexact meanings by sentences, we obtain complete sentences expressing fixed propositions. Thus, (1) - (4) become:

(1') It is raining in Lvov at the time $t$;

(2') This flower smells pleasantly for the person $P$;

(3') Cold bath is healthy for the person $P$;

(4') According to the moral view $M$, it is morally wrong to conceal truth

respectively. Converting incomplete sentences into propositions, complete by definition, result in possessing definite logical values by the latter. One can eventually speak about truth or falsehood of sentences, if it is known which propositions are expressed by them. Twardowski offered two other arguments against alethic relativism. Firstly, relativism confuses truth of $A$ and the knowledge that $A$ is true. Secondly, this view violates the principle of the excluded middle and the principle of non-contradiction, which are the fundamental laws of logic. However, this principles should be applied not to sentences, but to propositions. If $A$ is a proposition, not- $A$ is as well. Now, $A$ and not- $A$ cannot be both true and exactly one from this pair is true, but the second is false. Twardowski did not mention any representative of relativism in 1900. In (TWARDOWSKI [1975]), he exemplifies alethic relativism by the account of truth proposed by pragmatism.

It is convenient to introduce some terminology related to Twardowski's considerations with respect to temporal aspects of having logical values by propositions being their their bearers. We say that truth and falsity are omnitemporal, that is, if $A$ is true (false), then $A$ is true (false) at every time (and reversely, of course). $A$ is sempiternally true (false) if and only if provided that $A$ is true (false) at time $t$, it is also true (false) at every time earlier than $t .^{5}$ Finally, $A$ is eternally true if and only if, provided that it is true at time $t$, it is also true at every time later than $t$. A very interesting question consists in the relation of absoluteness of truth to its omnitemporality, sempiternality and eternality.

In 1913 took place a very hot debate between Kotarbiński and Leśniewski. The former (see KOTARBIŃSKI [1913]) defended eternality of truth, but rejected its sempiternality. His concerns was the possibility of creative human action. According to Kotarbiński, the existence of a such action is inconsistent with sempiternality of truth. Consequently, he admits eternal truths which are not

\footnotetext{
${ }^{5}$ We can also say that truth (falsity) is predetermined if it is sempiternal (I will omit the reference to falsity in most further remarks). It immediately suggests a connection of properties of truth with the perennial problem of determinism and indeterminism. However, this question was not touched in Polish discussions about alethic absolutism and relativism. I will omit the reference to falsity in most further remarks.
} 
sempiternal. Consider an object $O$ created by a human action in time $t$. Clearly, $O$ does not exist before $t$. Kotarbiński, following Brentano, defines truth by the following formula:

(5) A proposition $A$ affirming an object $O$ is true if and only if $O$ exists; $A$ is false otherwise.

Now, if $O$ does not exist, $A$ is neither true nor false. Consequently, $A$ cannot be true or false and it is indefinite. By contraposition, $A$ is definite if and only if $A$ is true or false. Consider the following statements:

(6) For any $A$, either $A$ or not- $A$ is true;

(7) For any $A, A$ is true or false;

(8) For any $A$, if $A$ is true, not- $A$ is false,

as possible forms of the principle of the excluded middle. If we adopt that $A$ is true is equivalent with $A$ is not-false, (4) and (5) express the classical excluded middle. However, the admission of indefinite sentences is at odds with the equivalence of 'true' and 'not false', Consequently, (6) and (7) have a restricted validity, contrary to (8) which is universal. These considerations lead to

(9) For any $A, A$ is definite or $A$ is indefinite,

as a generalized (or modified) the principle of the excluded middle. Clearly, (9) is fully consistent with qualifying some propositions as neither true not false, but just indefinite. ${ }^{6}$

Leśniewski very strongly criticized Kotarbiński's account of truth tolerating indefinite propositions. He sarcastically remarked (see LEŚNIEWSKI [1913], p. 104, page reference to English translation):

No truth can be created! The need to stress and energetically instill this view in others is growing now that, at the present stage of development of Polish 'philosophy', voices claiming that truths are created are clamoring even more loudly. It is not only the protagonists of all sorts of 'Pragmatism', 'Humanism' 'Conventionalism, 'Instrumentalism', 'previdionism', etc. that speak of the 'creation' of truths', i.e. not only the representatives of these 'philosophical' trends according to whom a judgment 'becomes' true: if it is useful for the preservation of the species; if it is an effective instrument of thought; if it assists in predicting reality, etc. That is not only those for whom, like for the Greek sophist Protagoras and the Polish sophist Florian Znaniecki, 'man is is the

\footnotetext{
${ }^{6}$ Kotarbiński iks sometimes regarded as a forerunner of many-valued logic. See WOLEŃSKI [1990] for further remarks. Perhaps one remark is in order. Kotarbiński suggest nothing about the nature of indefinite propositions. In particular, he does not explains whether the indefiniteness should be considered as an additional logical value or a truth-value gap.
} 
measure of all things' and thus a 'measure of truth'. Slowly, truth begin to become 'created' even by the representatives of the cam which has gathered at the Lvov University around Professor Kazimierz Twardowski; that is the camp, whose members have for such a long time believed that a judgment is always absolutely truth, i.e. that is true independently of whether it is useful of damaging; whether it helps to forecast the future or not; whether a scholar felt like 'creating' ther given truth and he did, or refrained from such 'creation', etc. No truth can be created!

Although Kotarbiński is not mentioned in the above quotation, Leśniewski alludes to him as a person going against one of the most characteristic doctrines of Twardowski's school.

Leśniewski presented in his essay a very detailed criticism of Kotarbiński's view that some truths are eternal but not sempiternal. According to Leśniewski, a sentence (he used the nominalistic language in his works) of the type ' $a$ is $b$ ' is true if and only if the object signified by the term $a$ has a property signified by the predicate $b$. it is just the case that the sentence possesses the function of symbolizing. Two conditions must be satisfied for possessing this function. Firstly, the term $a$ cannot be empty, and secondly, the predicate $b$ must connote a property of the object denoted by the subject term. If these conditions are satisfied, if $A$ is true, not- $A$ is false. This suffices for grounding the law of the excluded middle for sentences possessing the function of symbolizing; this principle is violated by sentences with empty terms, because is $a$ is empty, ' $a$ is $b$ ' as well as its negation are false. Thus, although Leśniewski does not consider the excluded middle as a universally valid principle, he also rejects indefinite sentences. Assume that if a sentence $A$ is not false it is also not true. According to Leśniewski's semiotic claims, this sentence fails to possess a function of symbolizing and it simultaneously does not possess such a function. Leśniewski argues that these assumptions produce a contradiction. I will not reproduce Leśniewski's proof (by reductio ad absurdum) that a contradiction actually follows from premises adopted by Lesniewski (see WOLEŃSKI, SIMONS [1989], p. 401-402); this paper shows that Leśniewski argument is incorrect and must be supplemented by additional premises), where one can find which additional premises are to be add). The most important Leśniewski's result is following one:

(10) $A$ is eternal if and only if it is sempiternal.

Due to (10) every truth is omnitemporal. It is important to note that Leśniewski used only classical logic. I will return to this problem at the end of the present paper.

Although it was 1913 and no non-classical logic was suggested to copy with the problem of sempiternality and eternality of truth, Leśniewski-type arguments 
can be used by everybody who maintains that classical logical rules are sufficient to argue for the absoluteness of truth (see also below). Kotarbiński accepted Leśniewski's criticism and resigned from indefinite propositions and the view that truth can be eternal, but not sempiternal. In KOTARBIŃSKI [1929] he repeated Twardowski's arguments against relativism and considered truth as an absolute property of sentences (he also became a nominalism). Twardowski himself (see TWARDOWSKI [1971]); this paper was written about 1913)) joined Lesniewski in his criticism of Kotarbiński. Leśniewski did not return to the problem of temporality of truth in his later writings. However, he proposed (see LEŚNIEWSKI [1931]) certain interpretation of the phrase

(11) ' $a$ is $b$ ' is true at time $t$.

Leśniewski proposed to read (11) as

(12) ' $a$ is $b$ at time $t$ ' is true.

This allows a simple interpretation of tensed sentences as absolutely true or false, because the letter $t$ is a parameter, not functions as a variable. It also seems that constant Leśniewski's opposition against many-valued logic was motivated by his strong feeling that truth is omintemporal.

Łukasiewicz's standpoint toward alethic absolutism and relativism is connected with many-valued logic (ŁUKASIEWICZ [1922], [1930]). His discovery of this kind of logic was strongly motivated by the question of determinism and indeterminism. Łukasiewicz argued that two-valued (bivalent) logic supplemented by the principle of causality implies strong determinism. ${ }^{7}$ Consider the simplest case, namely three-valued logic. Future contingencies, that is sentences about future events exemplify those sentences which are neither true nor false in the moment of their issuing. Let $A$ be such a sentence. We have (the symbol $v(A)$ means "the value of a sentence $A)=v($ not $-A)=1 / 2$ ). This sentence became true or false in the future. Otherwise speaking, sentences with the third value, denoted by the fraction $1 / 2$ become true or false.

Now the question arises whether Łukasiewiczian semantics implies alethic relativism. Clearly, truth is not sempiternal on Lukasiewicz's views, because if $A$ is a future contingency and $v(A)=1$ at time $t$, it can have another logical value in moments earlier than $t$. On the hand, if $A$ becomes true (or false) at time $t$, it remains true (or false) for ever. Consequently, truth is eternal, although not sempiternal. According to Łukasiewicz, this consequence is coherent with alethic absolutism, because (I use another language than Łukasiewicz's did) this view concerns changing truth of $A$ into falsity but not becoming $A$ true. The property of eternality makes truth stable and it suffices for alethic absolutism.

7 Logical determinism is the view that (strong) determinism follows from the principle of bivalence. According to Łukasiewicz logic does not suffice for justify determinism from. 
Two remarks are in order here. Firstly, we should distinguish strong absolutism and weak absolutism. The former considers truth as omnitemporal (sempiternal and eternal), but the latter attributes to truth eternality only. Leśniewski was a strong absolutist but Łukasiewicz accepted the weak form of alethic absolutism. Secondly, we can state a generalized version of the discussed problem. Typically, absolutism and relativism are discussed with respect to truth. Adding falsity does not create any specific problem. The situation changes, when we take into account other logical values, for instance, the third value in Lukasiewicz's semantics. Examples suggest that it is not eternal. On the other hand, if we accept that not possibilities will be realized in the future, at least some neither-truth-nor-falsehoods can be eternal with respect to to their logical values. Similar considerations concern sempiternality of the third value. It seems that various ontological circumstances can influence specific semantic properties of sentences having other logical values that truth or falsity.

Tarski did not explicitly address himself to the philosophical problem of alethic abslolutism. ${ }^{8}$ However, he mentioned the (see TARSKI [1933], p. 199; pagereference to English translation) that the concept of correct (or true) sentence in an individual domain, used in the Hilbert school, is of a relative character. Hence, he indirectly suggested that the semantic definition of truth as formulated in TARSKI [1933] is absolute. However, it only means that the absolutist semantic truth-definition is formulated for the entire domain $D$ of individuals. Speaking more philosophically, this domain can be identified with the world in its integrity. ${ }^{9}$ Now, if someone selects a sub-domain $D^{\prime} \subset D$, a relativized concept of truth is obtained. At least three reasons justify an analysis of the semantic concept of truth as related to the alethic absolutism/relativis problem. Firstly, Tarski explicitly considered his truth-definition as an answer to an epistemological issue. Hence, we can try to address typical epistemological problems to the definition in question, even if Tarski was silent about them. Secondly, Tarski relativized truth to a language. Thirdly, Tarski implicitly in TARSKI [1933] and explicitly in his later works, relativized truth to a model $M$. Summing up the second and third point, Tarski's analysiss concerned the phrase

(13) a sentence $A$ of a language $L$ is true in a model $\mathbf{M}$.

And now we encounter the question whether (13) implies that truth is relative.

It was Kokoszyńska (see KOKOSZYŃSKA [1936a], [1936b], [1948], [1951]) who offered an absolute interpretation of the semantic definition of truth.

\footnotetext{
${ }^{8}$ Jan Tarski, Alfred's son, told mi once that his (Jan's) father considered absoluteness as a very important property of truth. However, it could be that (Alfred) Tarski was thinking about an ethical problem, not epistemological one.

${ }^{9}$ However, it is very likely that Tarski was thinking about mathematical domains and their subdomains.
} 
According to Kokoszyńska the predicate 'is true' is incomplete and can be qualified in various ways, for examples, by reference to circumstances $C$. A sentence $A$ is relatively true if and only if there exist circumstances $C$ and $C^{\prime}$ such that $A$ is true with reference to $\mathrm{C}$ and not- $A$ is true with reference to $C$ '. This relativism is proper. It can be radical, provided that for every sentence $A, A$ is true with reference to circumstances $C$ and it negation is true with reference tom circumstances $C^{\prime}$, or moderate, provided that we have do with truthrelativity of some sentences only. Moreover, we have improper relativism consisting in relativisation to models (possible worlds). More specifically, if $A$ is true in one model, let say $\mathbf{M}$ and not- $A$ is true in another model, let say $\mathbf{M}$ ', this situation leads to improper relativism. Although proper relativism tolerates the change of logical values of all or some sentences, dependently of circumstances, improper relativism entails the stability of truth and falsity in models.

Kokoszyńska's views require some comments and supplements. First of all, she précised Twardowski's criticism of alethic relativism. In fact, she repeated Twardowski's arguments in setting them as using the concept of circumstance as a general relativiser. Secondly, Kokoszyńska assumed classical logic. Her definition would qualify so-called dialetheias, that is, pairs of sentences of the type ' $A$ and not- $A$ ' which can be true, as true. Paraconsistent logic (more precisely, one of its versions) admits dialetheias. Hence, we have a problem how paraconsisten logic is related to the absolutism/relativism distinction. If $d$ is a dialetheia with $A$ and not- $A$ as its members, both components of $d$ can be true in the same circumstances. His means that paraconsistent logic (with dialetheias) does not imply even moderate dialethic relativism. I note this problem without entering into its more detailed analysis. Thirdly, many-valued logic proper moderate relativism, because if $v(A)=1 / 2$, it becomes true or false dependently of some circumstances. It suggests that improper relativism considers truth (falsity) as omnitemporal and should be qualified as absolutism.

Kokoszyńska understood sentences as equipped with fixed meanings. Consequently, she could resign from the distinction (maintained by Twardowski) of sentences as incomplete utterances and thereby not prop[er truth-bearings) and propositions as items with complete meaning and being proper truth-bearers. This observation indirectly leads to a Twardowski-like reading of Tarski. The latter defined the concept of truth via the notion of satisfaction. Usually we speak about satisfaction of open formulas (formulas with free variables). For example, the formula ' $x$ is a logician' is satisfied by Tarski, but not by Heidegger. Sentences are formulas without free variables, for instance, 'Tarski is a logician' or 'there is such $x$, that $x$ is not a logician'. Tarski's ingenious observation was that if sentences (closed formulas) are a special case of open formulas and sentences are true or false, truth (falsity) should be considered as special cases of satisfaction (non-satisfaction). Since we 
can prove that for any sentence (a closed formula) $A$ is satisfied by all infinite sequences for a model $\mathbf{M}$ or is satisfied by no such sequence, it is natural to define truth of $A$ as its satisfaction by all sentences and its falsity as satisfaction by no sequences. ${ }^{10}$ Now we can interpret sentences in Twardowski's sense as open formulas. In fact, the utterances 'it is raining today' and 'it is raining here' mean 'it is raining in time $x$ considered as today' and 'it is raining in the place $x$ considered as here'. ${ }^{11}$ Consequently, we open formulas are relatively true (false) depending on circumstances (interpretations of free variables), but sentences are absolutely true, because (see note 10) their logical values are conditioned by the structure of models (possible worlds, etc.). Now, one could eventually observe that models are circumstances. ${ }^{12}$ Thus, if we intend to interpret the semantic definition of truth as absolute, we need to justify that $\mathbf{M}$ in the phrase 'a sentence $A$ is true in a model $M^{\prime}$ ' is not a circumstance in Kokoszyńska's sense.

Here is an argument that relativisation of truth to models is consistent with absolutism understood as the thesis that truth is omnitemporal (I follow WOLEŃSKI [2015]). The argument concerns future contingencies, that is, sentences which can be true or false in the future. I will identify possible worlds with models of maximally consistent sets and use the concept of branchability (ASSER [1972], 168-169) as defined by ('iff' stands for 'if and only if'):

(14)(a) a set $\mathbf{X}$ of formulas branches at a formula $A$ iff the sets $\mathbf{X} \cup\{A\}$ and $\mathbf{X} \cup\{\neg A\}$ are consistent;

(b) a set $\mathbf{X}$ is branchable iff there is a formula $A$ at which $\mathrm{X}$ branches;

(c) a set $\mathbf{X}$ is branchable iff $\mathbf{X}$ is a consistent and incomplete set of sentences.

Let $\mathbf{X}$ be a consistent set of sentences and $A$ be a sentence independent of $\mathbf{X}$. Thus, due to the independence of $A$ with respect to $\mathbf{X}$, this set is incomplete and the sets $\mathbf{X}^{\prime}=\mathbf{X} \cup\{A\}$ and $\mathbf{X}^{\prime \prime}=\mathbf{X} \cup\{A\}$ are consistent. Consequently, the conditions listed in (14) are fulfilled and $\mathbf{X}$ branches at $A$. Note that we do not need to assume that the sets $\mathbf{X}^{\prime}$ and $\mathbf{X}$ ' are maximally consistent. The diagram $(\Delta)$ provides a scheme of this situation:

\footnotetext{
${ }^{10}$ A warning. Sequences of objects are not to be understood as facts. The former are a technical device used in the semantic truth-definition. The basic intuition behind defining truth via satisfaction is that if $A$ is a sentence, its logical value does not depend on valuation of bound variables (other not occur in sentences). Philosophically speaking, truth and falsity depends of how things are in a model $M$ assuming that sentences having logical values have fixed meanings. Tarski's claim that his definition is applicable only to interpreted languages should be interpreted as an assumption that meaning are given in advance.

${ }^{11}$ Of course, interpreting indexicals as hidden free variables is nothing new.

12 SUSZKO [1957] and HAACK [1978] interpret Tarski's original definition (that is, from TARSKI [1933] as absolute, but the predicate 'is true in M' as expressing a relative concept of truth.
} 


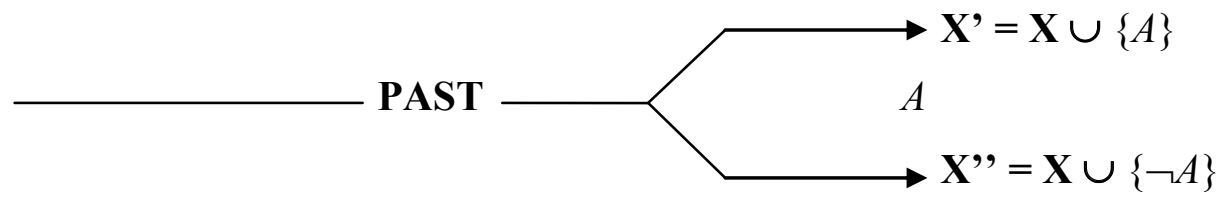

Let $A$ be a sentence uttered at $t$ fixed as present and refers to a contingent future event (this means that $\mathbf{X}$ is branchable, that is $A$ is independent of $\mathbf{X}$ ). Assuming that $\mathbf{X}$ consist of all truths about the past, it is consistent (PAST is its model), and $\mathbf{X}^{\prime}$ and $\mathbf{X}^{\prime}$ ' are consistent as well and they have models $\mathbf{W}^{\prime}$ and $\mathbf{W}$ ', respectively. We change the diagram $(\Delta)$ into $\left(\Delta^{\prime}\right)$

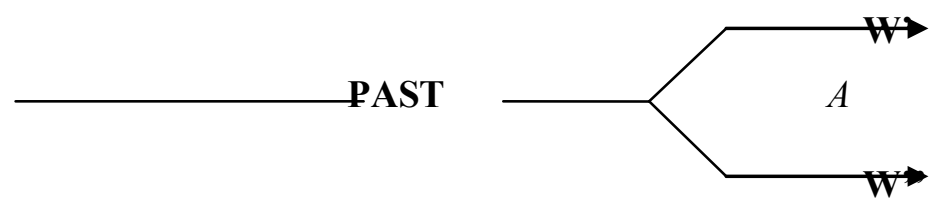

PAST can be considered as the initial segment of both $\mathbf{W}$ ' and $\mathbf{W}$ '. Otherwise speaking, W' and W', enlarge PAST; intuitively PAST comprises everything what happened until the moment $t$ (including this moment itself). Moreover, W' and $\mathbf{W}$ ' are parts of different possible worlds, that is, models of consistent sets. They are different, because the world W' validates $A$, but the world $\mathbf{W}$ ', verifies $\neg A$. PAST can be identified with the initial segment of the real world $\mathbf{W}^{\mathbf{R}}$, which grows through time. Depending on what will actually happen in the future, PAST will enlarge to $\mathbf{W}$ ' or $\mathbf{W}$ ' (for simplicity, I neglect further possible future cases of branching).

Truth-conditions for future contingencies can be easily stated by applying the standard possible world semantics associated with classical modal logic. In particular, sentences about future contingent facts are modals with the possibility operator $\diamond$. Suppose that $\diamond A$ is such a sentence. It is true in the real world $\mathbf{W}^{\mathbf{R}}$ if and only $A$ is true at least in one possible world accessible from $\mathbf{W}^{\mathbf{R}}$ (in fact, PAST generates the accessibility relation); denote this world by W'. Consequently, due to the contingency of the fact described by $A$, the sentence $\checkmark \neg A$ is true in $\mathbf{W}^{\mathbf{R}}$ if there is a possible world $\mathbf{W}$ " in which $\neg A$ is true is true. The world $\mathbf{W}$ ' and $\mathbf{W}$ ' are just (different) worlds sutitable for validating $\diamond A$ and $\checkmark \neg A$ in the real world. Assume that $A$ is true in the future. This means that $A$ is true in $\mathbf{W}$ '. However, since PAST and $\mathbf{W}^{\prime}$ are segments of $\mathbf{W}^{\mathbf{R}}, A$ cannot be false in PAST. So if $A$ is true, its truth is omnitemporal. Similar reasoning concerns the situation in which $\neg A$ is true. ${ }^{13}$ Now we can return to Leśniewski

\footnotetext{
${ }^{13}$ This argument also refutes the view that classical logic entails strict determinism.
} 
claim expressed by (10).Assume that $A$ is true at a moment $t$. At first, we will prove that sempiternality entails eternality. If $A$ is true sempiternally, it is true at every $t^{\prime} \leq t$. Since the branching moment is critical, we assume that $t$ is just this parameter. Consequently, $A$ is true in $\mathbf{W}^{\prime}$ or $A$ is true in $\mathbf{W}^{\prime \prime}$. Furthermore, $A$ is true in $\mathbf{M}^{\prime}=\mathbf{P A S T}+\mathbf{W}^{\prime}$ or $A$ is true in $\mathbf{M}{ }^{\prime}$ ' $=$ PAST $+\mathbf{W}^{\prime}$ '. This implies that $\neg A$ is false in $\mathbf{M}$ ' $=$ PAST $+\mathbf{W}$ ' or $\neg A$ is false in $\mathbf{M}$ ' $=$ PAST $+\mathbf{W}$ '. Clearly, $A$ cannot change its logical value in a model belonging to $\{\mathbf{M}$ ', M' $\}$ without producing inconsistency. Thus, if $A$ is sempiternally true, it is eternally true as well. To prove the converse implication, suppose that $A$ is eternally true, that is, if $A$ is true at $t$, it is also true at any moment $t^{\prime} \geq \mathrm{t}$; of course, $A$ is true in $\mathbf{W}^{\prime}$ or $\mathbf{W}$ ' and a fortiori, in $\mathbf{M}$ ' or $\mathbf{M}$ '. Consider a moment $t$ ' $\leq t$. Assume that $A$ is false at $t^{\prime \prime}$. This means that $A$ is false in PAST. However, this implies that $A$ is false in $\mathbf{M}$ ' or M', contrary to our earlier assumption. Thus, if $A$ is eternally true, it is sempiternally true as well. This closed the proof that $A$ is sempiternally true if and only if $A$ is eternally true. Thus, truth in a model is omnitemporal and the semantic definition of truth defined the absolute concept of truth. ${ }^{14}$

\section{Reference}

ASSER, G. [1972], Einführung in die mathematische Logik, Teil II, Prädikatenkalkül der ersten Stufe. Leipzig: Teubner.

HAACK, S. [1978], Philosophy of Logics, Cambridge: Cambridge University Press.

KOKOSZYŃSKA, M. [1936a], "Über den absoluten Wahrheitsbegriff und andere sementische Begriffe”, Erkenntnis 6, 143-165; repr. in Peirce, Woleński 1988, 276-292.

KOKOSZYŃSKA, M. [1936b], "Syntax, Semantik Und Wissenschafrtslogik”, Actes du Congrés International de Philosophie Scientifique, vol. 3, Paris: Herman, 9-14; repr. in Peirce, Woleński [1988], 271-275.

KOKOSZYŃSKA, M. [1948], "What means 'Relaticity of Truth"”, Studia Philosopghica III, $167-176$.

KOKOSZYŃSKA, M. [1951], “A Refutation of the Relativity of Truth”, Studia Philosophica IV, $1-57$.

\footnotetext{
14 This conclusion must meet the existence of non-standard models. Let $T$ be an arbitrary consistent set of first-order sentences. Due to the Löwenheim-Skolem it has a non-standard model. The situation cannot be generally solved by going to higher-order logic. The only possibility to defend the view defended in this paper (and following the main tradition of the Lvov-Warsaw School) consists in saying that the problem consists of how to select the standard model, but not the absoluteness of truth. Putting this in another words: truth in every model is absolute, but the criteria of selecting standard models are pragmatic and conventional to some degree. If we select the standard model $\mathbf{M}$ as fixed, truth in $\mathbf{M}$ is absolute, but truth in non-standard models can be considered as relative but only relatively to our choice (see PRZEŁĘCKI [1969]).
} 
KOTARBIŃSKI, T. [1913], "Zagadnienie istnienia przyszłości” (The Problem of the Existence of Future), Przeglad Filozoficzny 16, 74-92, Eng. tr., The Polish Review (New York) 13, no. 3, 1968, $7-22$.

KOTARBIŃSKI, T. [1929], Elementy teorii poznania, logiki formalnej i metodologii nauk, Lwów: Ossolineum; Eng. tr. Gnosiology. The Scientific Approach to the Theory of Knowledge, Oxford: Pergamon Press.

LEŚNIEWSKI, S. [1912], “Czy prawda jest tylko wieczna, czy też wieczna i odwieczna?” (Is All Truth only True Eternally or It Is True without a Beginning; in Polish), Nowe Tory 18, 493-512; Eng. tr. in Leśniewski 1992, 86-114.

LEŚNIEWSKI, S. [1931], "O podstawach matematyki" (On the Foundations of Mathematics) $\S \S 10-11$, Przeglad Filozoficzny 34, 142-170; Eng. tr. in Leśniewski [1992], 351-382.

LEŚNIEWSKI, S. 1992: Collected Works, Dordrecht: Kluwer.

ŁUKASIEWICZ, J. [1922], “On Determinism”, in Łukasiewicz 1970, 110-128 (it is Eng. version of Łukasiewicz's Rector Speech in the academic year 1922/1923).

ŁUKASIEWICZ, J. [1930], "Philosophische Bemerkungen zu mehrwertigen Systemem der Aussagengenkalkül”. Comptes Rendus des Sèances de la Societé et de Lettres de Varsovie, Classe III 23, 51-77; Eng. tr. in Łukasiewicz 1970, 153-178.

ŁUKASIEWICZ, J. [1970], Selected Works. Amsterdam: North-Holland.

PEIRCE, D., WOLEŃSKI, J. (Hrsg.), Logischen Rarionalismus. Philosophische Scchriften der Lemberg-Warschauer Schule, Frankfurt a. M.: Athenäum.

PRZEŁĘCKI, M. [1969], Logic of Empirical Theories, London: Routledge and Kegan Paul.

SUSZKO, R. [1957], "Logika formalna a niektóre zagadnienia teorii poznania" (Formal Logic and Some Problems of the Theory of Knowledge), Myśl Filozoficzna 2(28), 27-56; 3(29), 34-69; przedruk in R. Suszko, Wybór pism, Warszawa: Polskie Towarzystwo Semiotyczne [1998], $67-108$.

TARSKI, A. [1933], Pojęcie prawdy w językach nauk dedukcyjnych (The Concept of Truth in Languages of Deductive Sciences), Warszawa: Towarzystwo Naukowe Warszawskie; Eng. tr., The Concept of Truth in Formalized Languages, in Tarski [1956], 152-278.

TARSKI, A. [1956], Logic, Semantics, Metamathematics. Papers of 1923 to 1938, Oxford: Clarendon Press, Oxford.

TWARDOWSKI, K. [1900], "O tzw. prawdach względnych", [in:] Księga Pamiatkowa Uniwestytetu Lwowskiego ku uczczeniu pięćscetnej rocznicy Fundacji Jagiellońskiej, Uniwersytet Lwowski, Lwów; Eng. tr. in Twardowski [1999], 147-169.

TWARDOWSKI, K. [1975], “Teoria poznania. Wykład w r. a. 1924/1925” (Theory of Knowledge. Lecture Course 1924-1925), Archiwum Historii Filozofii i Myśli Społecznej 21, 173222; Eng. tr. in Twardowski 1999, 181-239.

TWARDOWSKI, K. [1971], “O sceptycyzmie etycznym. Wykład w r. a. 1923-1924” (On Ethical Skepticis. Lecture Course 1923-1924), Etyka 9, 173-222; Eng. tr. in Twardowski, K., On Prejudices, Judgments and Other Topics in Philosophy, Amsterdam: Rodopi.

TWARDOWSKI, K. [1999], On Actions, Products and Other Topics in Philosophy, Amsterdam: Rodopi. 
WOLEŃSKI, J. [1990], "Kotarbiński, Many-Valued Logic and Truth”, [in:] Woleński, J. (ed.), Kotarbiński: Logic, Semantics and Ontology, Dordrecht: Kluwer; 190-197; repr. [in:] Woleński, J. Essays in the History of Logic and Logical Philosophy, Kraków: Jagiellonian University Press, Kraków, 115-120.

WOLEŃSKI, J. [2015], “An Analysis of Logical Determinism”, [in:] Themes from Ontology, Mind and Logic. Present and Past. Essays in Honour of Peter Simons, (ed.) by S. Lapointe, Leiden: Brill, 423-442.

WOLEŃSKI, J., SIMONS, P. [1989], "De Veritate: Austro-Polish Contributions to the Theory of Truth from Brentano to Tarski”, [in:] Szaniawski, K. (ed.), The Lvov-Warsaw School and the Vienna Circle. Dordrecht: Kluwer, 391-453. 